\title{
A Novel Small-molecule WNT Inhibitor, IC-2, Has the Potential to Suppress Liver Cancer Stem Cells
}

\author{
KENZO SETO $^{1 *}$, TOMOHIKO SAKABE $^{1 * \dagger}$, NORIKO ITABA $^{1}$, JUNYA AZUMI $^{1}$, HIROYUKI OKA $^{3}$, \\ MINORU MORIMOTO ${ }^{3}$, YOSHIHISA UMEKITA ${ }^{2}$ and GOSHI SHIOTA ${ }^{1}$ \\ ${ }^{1}$ Division of Molecular and Genetic Medicine, Department of Genetic Medicine and Regenerative Therapeutics, \\ Graduate School of Medicine, and ${ }^{2}$ Division of Organ Pathology, \\ Department of Pathology, Faculty of Medicine, Tottori University, Yonago, Japan; \\ ${ }^{3}$ Research Center for Bioscience and Technology, Tottori University, Koyama, Japan
}

\begin{abstract}
Background/Aim: The presence of cancer stem cells (CSCs) contributes to metastasis, recurrence, and resistance to chemo/radiotherapy in hepatocellular carcinoma (HCC). The WNT signaling pathway is reportedly linked to the maintenance of stemness of CSCs. In the present study, in order to eliminate liver CSCs and improve the prognosis of patients with $\mathrm{HCC}$, we explored whether small-molecule compounds targeting WNT signaling pathway suppress liver CSCs. Materials and Methods: The screening was performed using cell proliferation assay and reporter assay. We next investigated whether these compounds suppress liver CSC properties by using flow cytometric analysis and sphere-formation assays. A mouse xenograft model transplanted with CD44-positive $\mathrm{HuH7}$ cells was used to examine the in vivo antitumor effect of IC-2. Results: In HuH7 human HCC cells, 10 small-molecule compounds including novel derivatives, $I C-2$ and $P N-3-13$, suppressed cell viability and WNT signaling activity. Among them, IC-2 significantly reduced the CD44-positive population, also known as liver CSCs, and dramatically reduced the sphere-forming ability of both CD44-positive and CD44-negative HuH7 cells. Moreover, CSC marker-positive populations, namely CD90-positive HLF cells, CD133-positive HepG2 cells, and epithelial cell adhesion
\end{abstract}

*These Authors contributed equally to this study.

\footnotetext{
$\dagger$ Present address: Division of Organ Pathology, Department of Pathology, Faculty of Medicine, Tottori University, Yonago, Japan.

Correspondence to: Professor Goshi Shiota, MD, Ph.D., Division of Molecular and Genetic Medicine, Department of Genetic Medicine and Regenerative Therapeutics, Graduate School of Medicine, Tottori University, Nishi-cho 86, Yonago 683-8504, Japan. Tel.: +81 859386435, Fax: +81 859386430, e-mail: gshiota@med.tottori-u.ac.jp
}

Key Words: WNT/ $\beta$-catenin signal, small molecule compound, cancer stem cell, hepatocellular carcinoma. molecule-positive cells, were also reduced by IC-2 treatment. Finally, suppressive effects of IC-2 on liver CSCs were also observed in a xenograft model using CD44-positive $\mathrm{HuH7}$ cells. Conclusion: The novel derivative of small-molecule WNT inhibitor, IC-2, has the potential to suppress liver CSCs and can serve as a promising therapeutic agent to improve the prognosis of patients with $\mathrm{HCC}$.

A wide range of tumor types are reportedly composed of multiple cell populations (1). Tumor heterogeneity arises due to clonal evolution, effects of the tumor microenvironment, and the existence of cancer stem cells (CSCs). CSCs possess the capacity for unlimited self-renewal, as well as giving rise to progeny cells $(2,3)$. The aberrant differentiation into various types of cancer cells from CSCs provides a mechanism for generating phenotypic and functional tumor heterogeneity (1). In addition, we reported that the presence of CSCs serves as a prognostic marker for overall survival in patients with hepatocellular carcinoma (HCC), suggesting that undifferentiated CSCs are responsible for tumor growth and disease progression (4). Recent studies suggested the existence of an intimate relationship between liver stem cells and primary liver cancer according to the following CSC hypothesis. Firstly, a large amount of DNA damage accumulates in liver stem cells over a long life-span because these cells have long-term repopulating capability and longevity $(5,6)$. Secondly, the heterogeneity of liver cancer can be explained by the differentiation of liver cancer stem cells into various types of cancer cells $(6,7)$. Thirdly, the capacity for self-renewal and proliferation of liver stem cells are enhanced by damage to mature hepatocytes. As a result, the risk of mutation that facilitates the malignant transformation is significantly increased in liver stem cells.

CSCs are a small cell population that can self-renew and differentiate into various types of cancer cells; therefore, CSCs can accelerate and maintain tumor formation and progression. In HCC, the presence of liver CSCs is also reportedly associated with tumor heterogeneity, metastasis, recurrence, poor 
prognosis, and resistance to chemo/radiotherapy (8-10). Since CSCs behave similarly to normal stem cells, it is expected that WNT, Notch, and, Hedgehog signaling pathways are critically involved in the acquisition and maintainance of stem cell-like properties of CSCs (11). Moreover, it is interesting that these pathways are frequently dysregulated in a wide variety of cancer types, and especially in CSCs. In general, these signaling pathways are thought to be potential targets for developing more effective antitumor drugs, because CSCs are responsible for tumor recurrence, metastasis, and resistance to conventional chemo/radiotherapy (12). Among them, a growing body of evidence supports the critical role of the WNT signaling pathway in CSCs (13-15). The WNT signaling pathway, which regulates crucial aspects of migration, proliferation, polarity, cell fate specification, and survival, is frequently up-regulated in HCC (16). Yamashita and colleagues reported that epithelial cell adhesion molecule (EpCAM)-positive cancer cells isolated from HuH7 HCC cell line exhibit WNT signal activation and liver CSC traits (17). Genetic and pharmacological suppression of the WNT signaling pathway inhibits CSC properties, including self-renewal, proliferation, and cell invasion, in several types of cancer $(18,19)$. Based on these findings, we focused on the WNT signaling pathway as a target for eliminating liver cancer and examined the effect of 10 existing WNT signal inhibitors and three newly synthesized derivatives of these inhibitors on liver CSCs.

\section{Materials and Methods}

Cell culture and reagents. Human HCC cell lines, HuH7, HepG2, and HLF, were obtained from the Japanese Collection of Research Bioresources Cell Bank (JCRB, Osaka Japan) and were maintained in Dulbecco's modified Eagle's medium (DMEM; Nissui Pharmaceutical, Tokyo, Japan) supplemented with $10 \%$ fetal bovine serum (FBS; MBL, Nagoya, Japan), glucose, and L-glutamine in a humidified atmosphere of $5 \% \mathrm{CO}_{2}$ at $37^{\circ} \mathrm{C}$. Three derivatives of WNT signal inhibitors, namely $\mathrm{HC}-1, \mathrm{PN}-3-13$, and IC-2, were synthesized in-house (20).

Cell viability assay. In order to determine the effects of smallmolecule compounds on the proliferation of $\mathrm{HCC}$ cells, $\mathrm{HuH} 7$ cells were seeded in 96-well plates and were incubated for $24 \mathrm{~h}$. After incubation, cells were treated with different concentrations of smallmolecule compounds for 24 to $96 \mathrm{~h}$. 5-Fluorouracil (5-FU) was used as a positive control. Cell viabilities at 24, 48, and $96 \mathrm{~h}$ were assessed using 10\% Cell Counting Kit-8 (Dojin Kagaku, Kumamoto, Japan) and calculated by measuring absorbance at $450 \mathrm{~nm}$ and $600 \mathrm{~nm}$ as reference wavelength.

Luciferase reporter assay. $\mathrm{HuH7}$ cells were stably transfected with pTCF4-CMVpro-GL4.2 containing t-cell factor 4 (TCF-4) motif as reported previously (20), and cultured with $2 \mu \mathrm{g} / \mathrm{ml}$ puromycin. The cells were incubated in a 96-well plate for $12 \mathrm{~h}$ and treated with different concentrations of small-molecule compounds. After treatment for $48 \mathrm{~h}$, relative luciferase activity was measured using the Steady-Glo Luciferase Assay System (Promega Corporation, Madison, WI, USA) according to the manufacturer's instructions. The luciferase activity of dimethyl sulfoxide (DMSO)-treated cells was defined as $100 \%$.

Flow cytometry. Flow cytometric analysis was performed as previously reported (4). HCC cell lines were treated with smallmolecule compounds for $48 \mathrm{~h}$. After incubation, harvested cells were incubated with blocking solution containing $0.5 \%$ bovine serum albumin, $0.5 \% \mathrm{FBS}$, and $2 \mathrm{mM}$ EDTA for $15 \mathrm{~min}$ at $4^{\circ} \mathrm{C}$. $\mathrm{HuH} 7$ and HepG2 cells were incubated with the primary antibodies to CD44 (1:100; Cell Signaling Technology, Danvers, MA, USA), EpCAM (1:1,600; Cell Signaling Technology), and CD133 (1:10; Miltenyi Biotec, Gladbach, Germany) for $10 \mathrm{~min}$ at $4^{\circ} \mathrm{C}$, and then with the secondary, goat anti-mouse IgG Alexa Flour 488 (Life Technologies Corp, Carlsbad, CA, USA) for $10 \mathrm{~min}$ at $4^{\circ} \mathrm{C}$. HLF cells were incubated with allophycocyanin (APC)-conjugated anti-CD90 (1:100; BD Biosciences, Franklin Lakes, NJ, USA) for $10 \mathrm{~min}$ at $4^{\circ} \mathrm{C}$. Propidium iodide (PI) was used to remove non-viable cells. CD44, EpCAM, CD133, and CD90 expression were analyzed and cells were sorted by Moflo XDP cell sorter (Beckman Coulter, Brea, CA, USA). Data analysis was performed by Summit Software (Beckman Coulter) and FlowJo software (Tree Star, Inc., Ashland, OR, USA).

Sphere-formation assay. The sphere-forming ability of cancer cells was determined as previously reported (4) . The CD44-positive and CD44-negative cells fractions from $\mathrm{HuH} 7$ cells $\left(5.0 \times 10^{4}\right.$ cells/well $)$ were seeded onto ultra-low attachment 24-well plate (Corning, Corning, NY, USA), and cultured in DMEM/Nutrient Mixture F-12 Ham (DMEM/F12; Sigma-Aldrich, MO, USA) containing $20 \mathrm{ng} / \mathrm{ml}$ human recombinant epidermal growth factor (EGF), $20 \mathrm{ng} / \mathrm{ml}$ human recombinant basic fibroblast growth factor $(\mathrm{bFGF}), 1 \times \mathrm{B} 27$ supplement (Gibco, Life Technologies Corp.), and L-glutamine for $24 \mathrm{~h}$. After incubation, cells were treated with $1 \%$ DMSO, $0.5 \mu \mathrm{M}$ 5-FU, $5 \mu \mathrm{M}$ ionomycin, $200 \mu \mathrm{M}$ PNU74654, $50 \mu \mathrm{M}$ IC-2, and $10 \mu \mathrm{M}$ PN-3-13, respectively. At 1 week after treatment, the number of spheres with $\geq 100 \mu \mathrm{m}$ diameter was counted in 10 fields per well using the ImageJ software.

Xenograft model of CD44-positive HuH7 cells in mice. The animal experiment was approved by the Institutional Animal Care and Use Committee of Tottori University (13-Y-42). Male non-obese diabetic/severe combined immunodeficient (NOD/SCID) mice were purchased from Charles River Laboratories Japan, Inc. (Kanagawa, Japan). Sorted CD44-positive cells were seeded onto ultra-low attachment 24 -well plate at $1.0 \times 10^{5}$ cells/well, and cultured with DMEM/F12 supplemented with $20 \mathrm{ng} / \mathrm{ml}$ recombinant human EGF, $20 \mathrm{ng} / \mathrm{ml}$ recombinant human bFGF, $1 \times$ B27 supplement, and Lglutamine for 1 week to allow the formation of spheres. The spheres derived from CD44-positive cells were mixed with Matrigel matrix (Corning) at a ratio of $1: 1$ and $0.1 \mathrm{ml}$ of the aliquot was subcutaneously injected into right flank of each NOD/SCID mouse. The mice were randomly divided into following three groups: (i) control group $(n=5)$; (ii) 5-FU-treated group ( $n=4)$; and (iii) IC-2treated group $(n=4)$. At 1 to 3 months after transplantation, DMSO, 5 -FU $(30 \mathrm{mg} / \mathrm{kg})$, or IC-2 $(50 \mathrm{mg} / \mathrm{kg})$ were intraperitoneally administered every 3 days for 18 days while tumor size was measured every 3 days. Tumor volumes were calculated using the following equation: (tumor volume; $\left.\mathrm{mm}^{3}\right)=($ length; $\mathrm{mm}) \times(\text { width; } \mathrm{mm})^{2} \times 0.5$. Statistical analysis. Statistical comparisons in this study were performed using Dunnett's test and Student's $t$-test. Differences with a value of $p<0.05$ was considered to be statistically significant. 


\section{Results}

Screening for small-molecule compounds exhibiting antitumor effect on liver CSCs. Based on our previous study $(20,21), 13$ small-molecule compounds were selected and screened to identify agents targeting liver CSCs. Among them, 10 compounds, namely NSC668036, quercetin, CGP049090. ICG-001, imatinib, ionomycin, hexachlorophene, PKF115584, PKF118-310. and PNU74654, have been reported to inhibit the WNT signaling pathway in colorectal cancer cells $(22,23)$. Another three small-molecule compounds HC-1, PN3-13, and IC-2 are newly synthesized derivatives of hexachlorophene, PNU74654, and ICG-001, respectively, reported in our previous study (20). We first examined whether these compounds suppress cell proliferation and WNT-mediated transcriptional activity in the $\mathrm{HuH7}$ cell line. Nine molecules out of 13, with the exception of NSC668036, quercetin, HC-1 and imatinib, suppressed both cell proliferation (Figure 1) and WNT-mediated luciferase activity (Figure 2). Interestingly, 5-FU did not affect luciferase activity up at concentrations up to $10 \mu \mathrm{M}$, but rather enhanced it at $50 \mu \mathrm{M}$. Considering these data, we selected seven compounds, namely ICG-001, ionomycin, hexachlorophene, PKF118-310. PNU74654, PN-3-13, and IC-2, and then investigated whether these compounds exhibit anti-CSC activity. Since we recently reported that total CD44 is a better prognostic marker than other liver CSC markers, including EpCAM, CD13, and CD44 variant 9 , in patients with HCC (4), we used total CD44 as a liver CSC marker in this screening. As shown in Figure 3, PNU74654, IC-2, and PN-3-13 significantly reduced the CD44-positive population, whereas no significant effects were observed with ICG-001, ionomycin, hexachlorophene, and PKF118-310. In contrast, although 5-FU increased the proportion of PI-positive dead or dying cells, the CD44positive population was increased, suggesting that 5-FU affects only CD44-negative cells and not CD44-positive cells.

Effect of small-molecule compounds on sphere-forming ability. Self-renewal capacity has been reported as a common functional feature of CSCs (2). Therefore, the sphere-formation assay was performed to clarify the effect of each compound on the function of liver CSCs. Representative images of sphere formation in CD44-positive and -negative cells treated with DMSO, 5-FU, PNU74654, IC-2, and PN-3-13 were shown in Figure 4A. The sphere-forming ability of CD44-positive DMSO-treated cells, was higher than that of CD44-negative cells, as previously reported (4). Less sphere formation and smaller spheres were found in cells treated with 5-FU, PNR74654, IC-2 and PN-3-13 (Figure 4A). Furthermore, the number of sphere produced by cells treated with 5-FU, PNU74654, IC-2, and PN-3-13 decreased compared with that of cells treated with DMSO (Figure 4B). However, when compared to CD44-negative cells, the suppressive effects on sphere-forming ability of CD44-positive cells remained smaller in cells treated with 5-FU, PNU74654, or PN-3-13. Interestingly, IC-2 treatment greatly suppressed the sphereforming ability of both CD44-positive and CD44-negative cells, suggesting that IC-2 potentially suppresses CSC properties.

Effect of IC-2 on cell viability of liver CSCs in comparison to non-CSCs. In order to gain further insights into the effect of IC-2 on liver CSCs, cell viability was assessed after IC-2 treatment of both CD44-positive and CD44-negative populations of $\mathrm{HuH7}$ cells (Figure 5A). Although 5-FU treatment significantly reduced the cell viability of the CD44-negative population, its effect was impaired against CD44-positive cells. Meanwhile, IC-2 treatment reduced cell viability of both CD44-positive and CD44-negative populations with similar efficiency. These data suggest that IC-2 treatment is effective not only against non-CSCs but also against CSCs, in contrast to 5-FU.

We next examined whether IC-2 affects other liver CSCs expressing CD90. CD133, or EpCAM. As shown in Figure 5B, IC-2 reduced the CD90-positive HLF cell population from $21.8 \%$ to $13.5 \%$, whereas this was not observed in 5-FU-treated HLF cells. Similarly, CD133-positive or EpCAM-positive HepG2 cell populations were also reduced by IC- 2 from $57.1 \%$ to $1.45 \%$, and from $76.2 \%$ to $51.1 \%$, respectively (Figure $5 \mathrm{C}$ and $\mathrm{D}$ ). These data suggest that IC-2 has the ability to suppress a wide range of liver CSCs.

In vivo effect of IC-2 on liver CSCs. Xenograft study using NOD/SCID mice subcutaneously transplanted with CD44positive $\mathrm{HuH7}$ cells was performed to investigate the antitumor effect of IC-2 against liver CSCs in vivo (Figure 6). In 5-FU-administered mice, tumor growth was significantly suppressed compared to that in the controls. As expected, more potent IC-2 manifested a more potent suppressive effect than 5-FU, suggesting that the suppression of CSCs by IC-2 would provide clinical benefits for patients with HCC.

\section{Discussion}

The WNT signaling pathway is often activated in HCC cells in agreement with the fact that this pathway has critical roles for liver CSCs $(16,17)$. This prompted us to investigate the antitumor effect of WNT signal inhibitors against liver CSCs. In the present study, we demonstrated that IC-2, derivative of ICG-001 recently synthesized in-house, efficiently suppresses liver CSC properties, including sphere-forming ability, cell proliferation, and tumor development in vivo.

In our screening experiments, the majority of WNT inhibitors showed suppressive effects on cell proliferation and WNT signaling activity in $\mathrm{HuH7}$ cells. However, although WNT signaling was suppressed by these inhibitors, liver CSC abilities were not affected by the inhibitors, 
A.

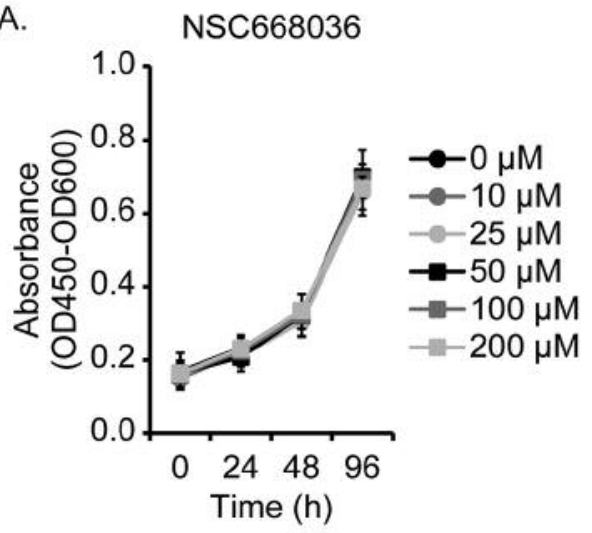

C.

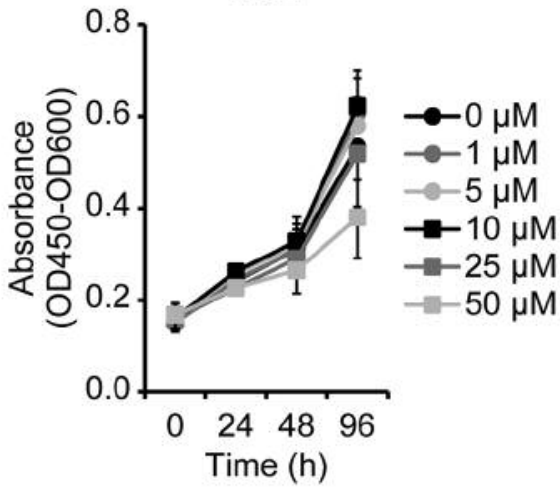

E.

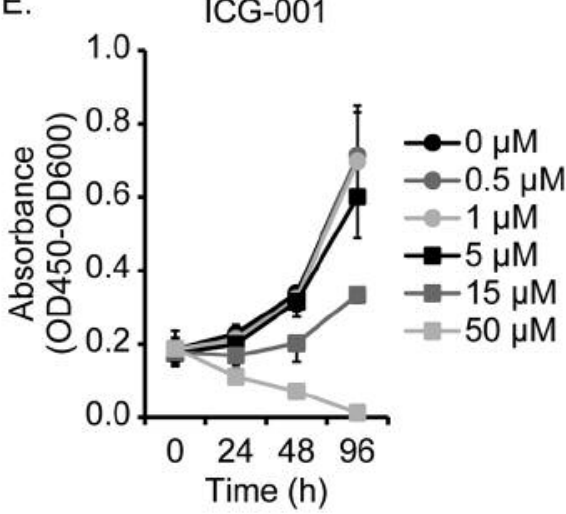

G.

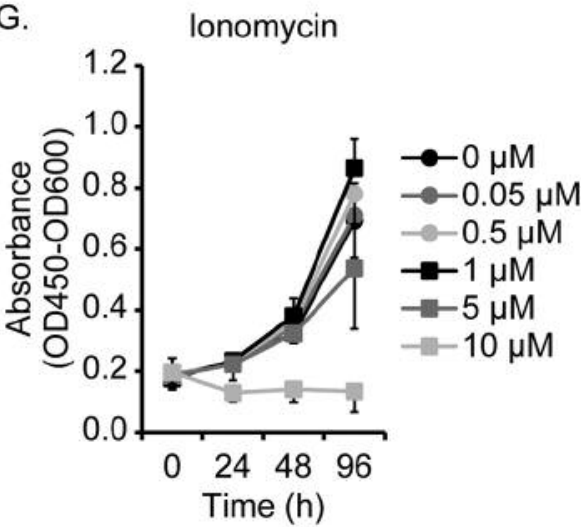

B. Quercetin

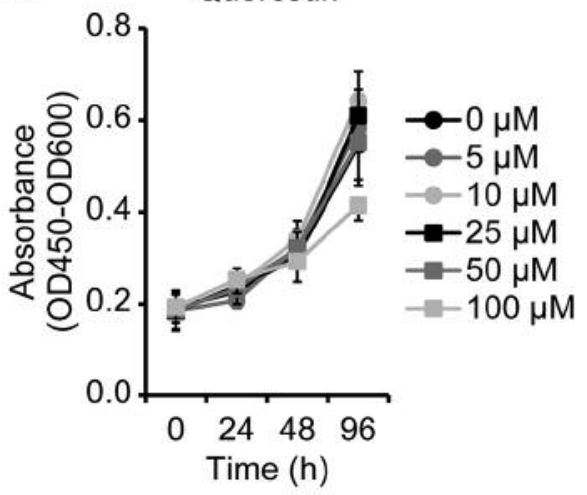

D.

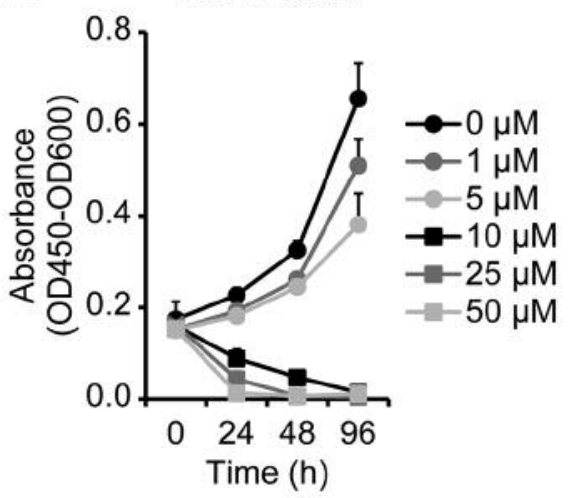

F.

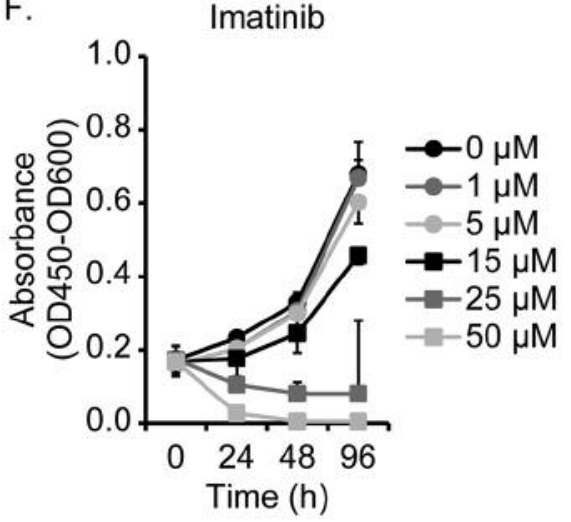

H. Hexachlorophene

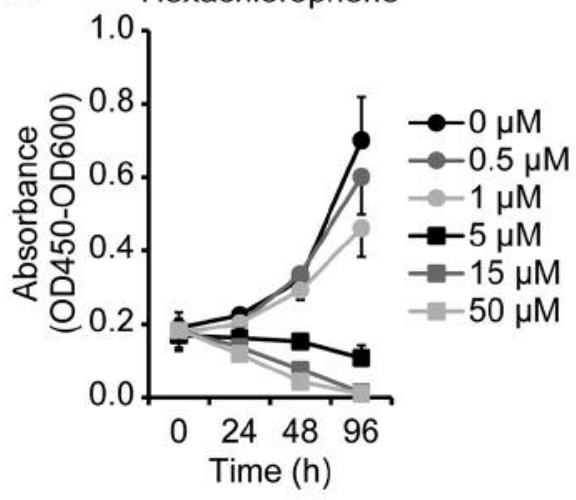



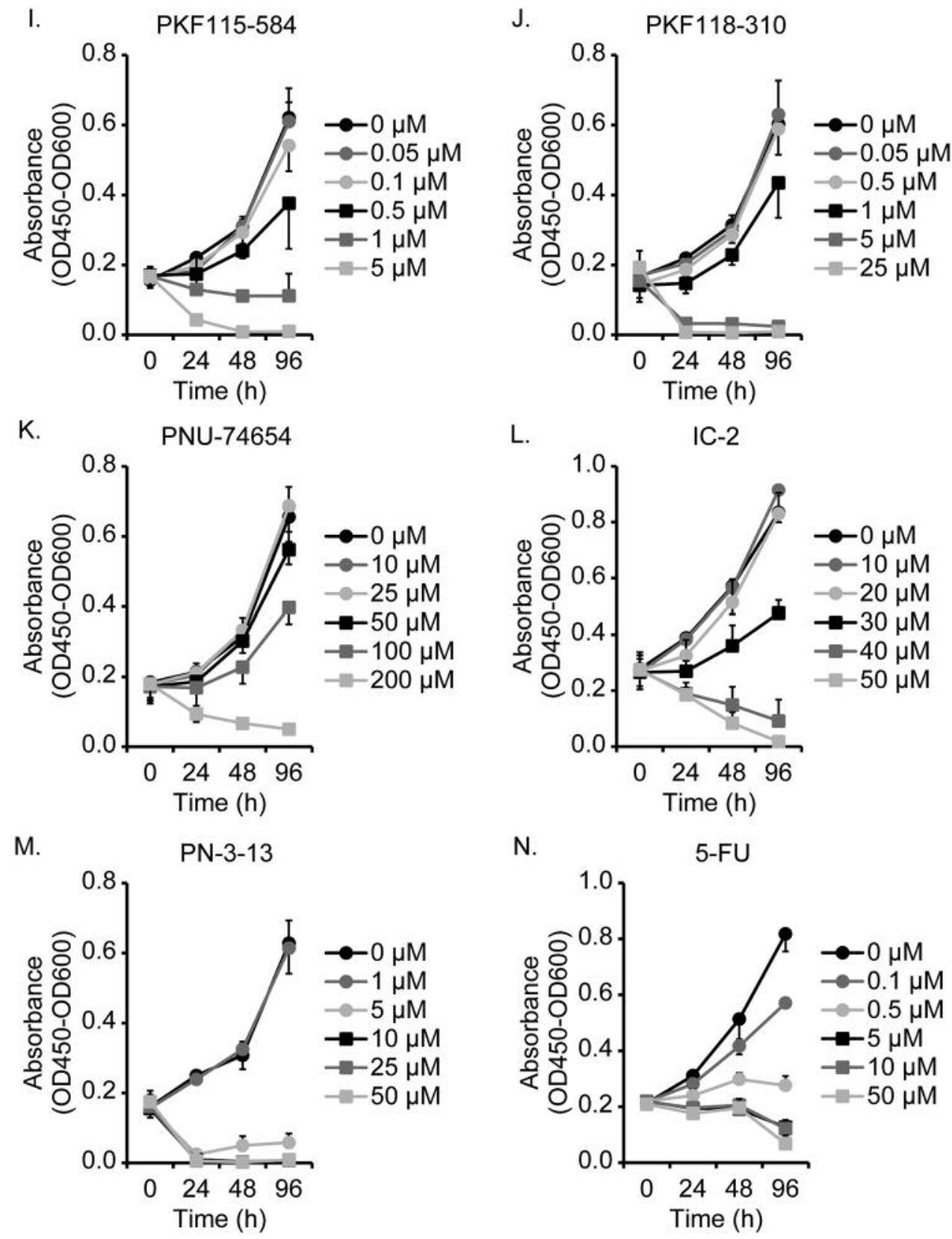

Figure 1. Time- and dose-dependent antitumor effect of small-molecule compounds on HuH7 cells. Viability of HuH7 cells treated with NSC668306 (A), quercetin (B), HC-1 (C), CGP049090 (D), ICG-001 (E), imatinib (F), ionomycin $(G)$, hexachlorophene (H), PKF115-584 (I), PKF118-310 (J), PNU-74654 (K), IC-2 (L), PN-3-13 (M), and 5-fluorouracil (5-FU) (N). Cell viability was determined using the WST assay at $0.24,48$, and 96 h. Data are shown as the mean $\pm S D(n=3)$.

except for IC-2. The underlying inhibitory mechanisms of these small-molecule compounds have been reported as follows. Hexachlorophene promotes $\beta$-catenin degradation via a proteasome-dependent manner (24). Ionomycin inhibits nuclear translocation of $\beta$-catenin (25). PKF115584, PKF118-310. CGP049090 and PNU-74654 inhibit the association of $\beta$-catenin with TCF of lymphoid enhancer factor (LEF) $(22,26,27)$. ICG-001, and possibly IC-2, binds to the transcriptional coactivator cAMP response elementbinding protein-binding protein (CBP) to disrupt the interaction of CBP with $\beta$-catenin (28). WNT-mediated transcriptional activation in tumor and embryonic stem cells 

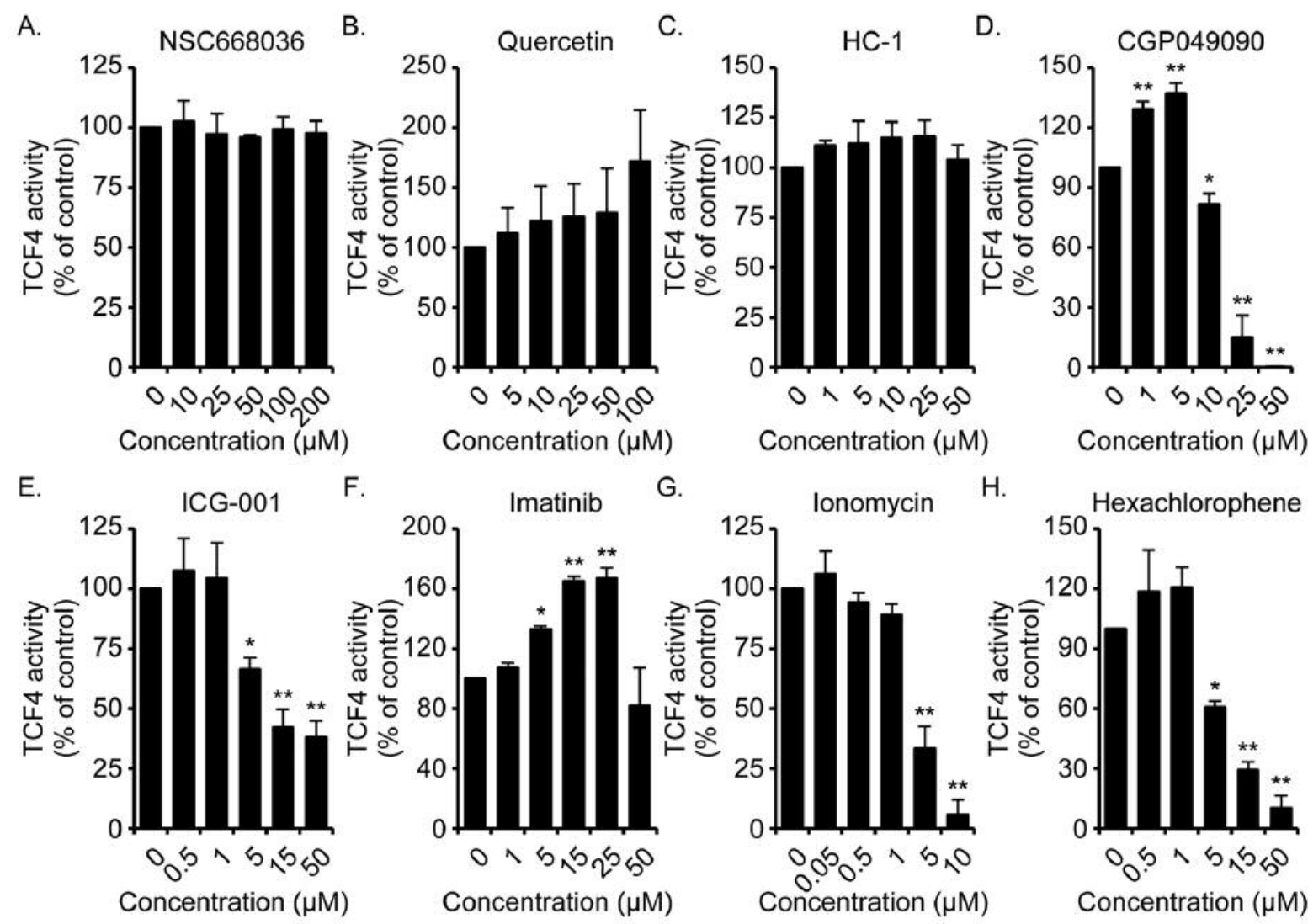

Concentration $(\mu \mathrm{M})$

Concentration $(\mu \mathrm{M})$
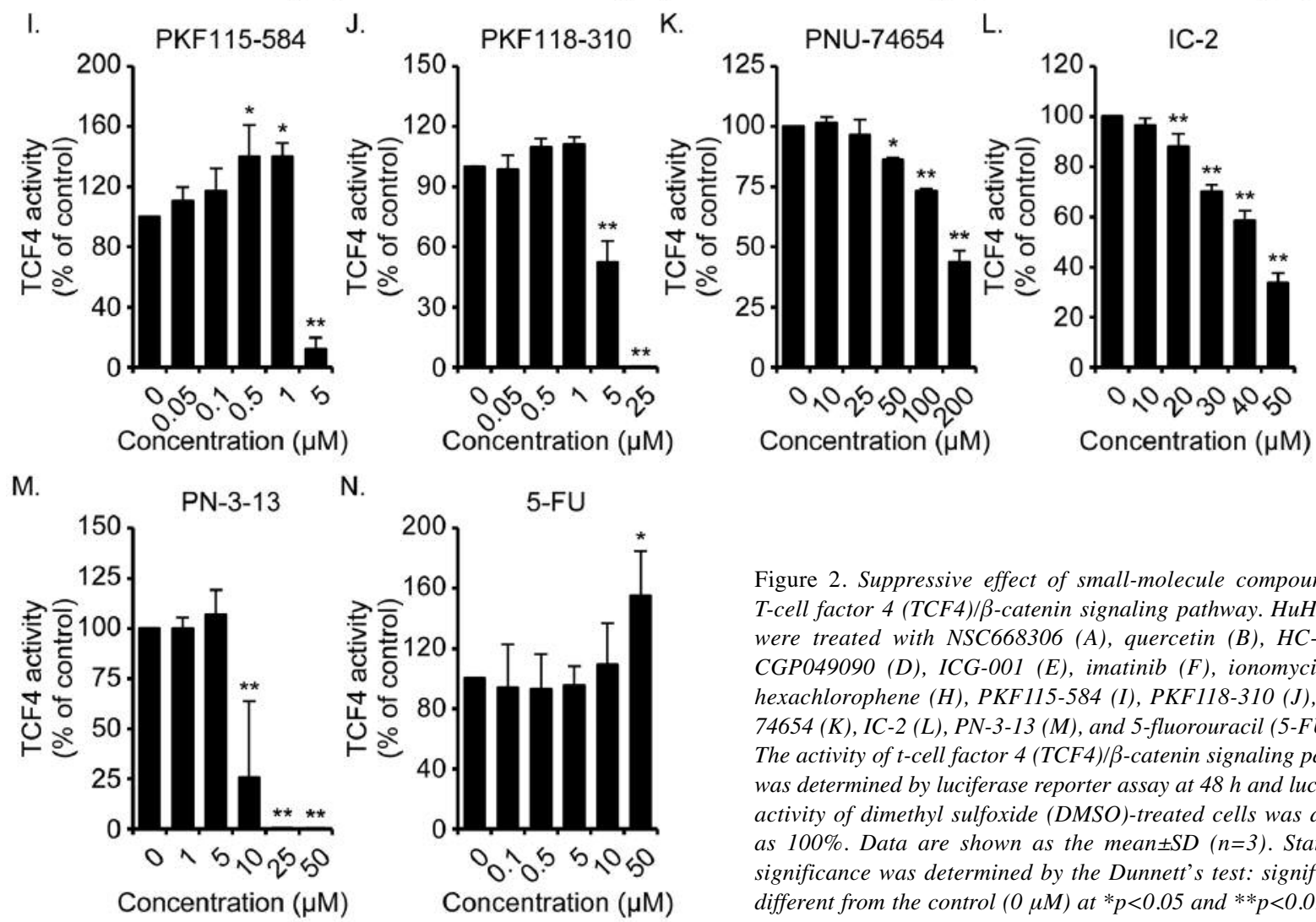

Figure 2. Suppressive effect of small-molecule compounds on T-cell factor 4 (TCF4)/ $\beta$-catenin signaling pathway. $\mathrm{HuH7}$ cells were treated with NSC668306 (A), quercetin (B), HC-1 (C), CGP049090 (D), ICG-001 (E), imatinib $(F)$, ionomycin $(G)$, hexachlorophene (H), PKF115-584 (I), PKF118-310 (J), PNU$74654(K), I C-2(L), P N-3-13(M)$, and 5-fluorouracil (5-FU) $(N)$. The activity of $t$-cell factor 4 (TCF4)/ $\beta$-catenin signaling pathway was determined by luciferase reporter assay at $48 \mathrm{~h}$ and luciferase activity of dimethyl sulfoxide (DMSO)-treated cells was defined as $100 \%$. Data are shown as the mean $\pm S D(n=3)$. Statistical significance was determined by the Dunnett's test: significantly different from the control $(0 \mu M)$ at $* p<0.05$ and $* * p<0.01$. 
A.
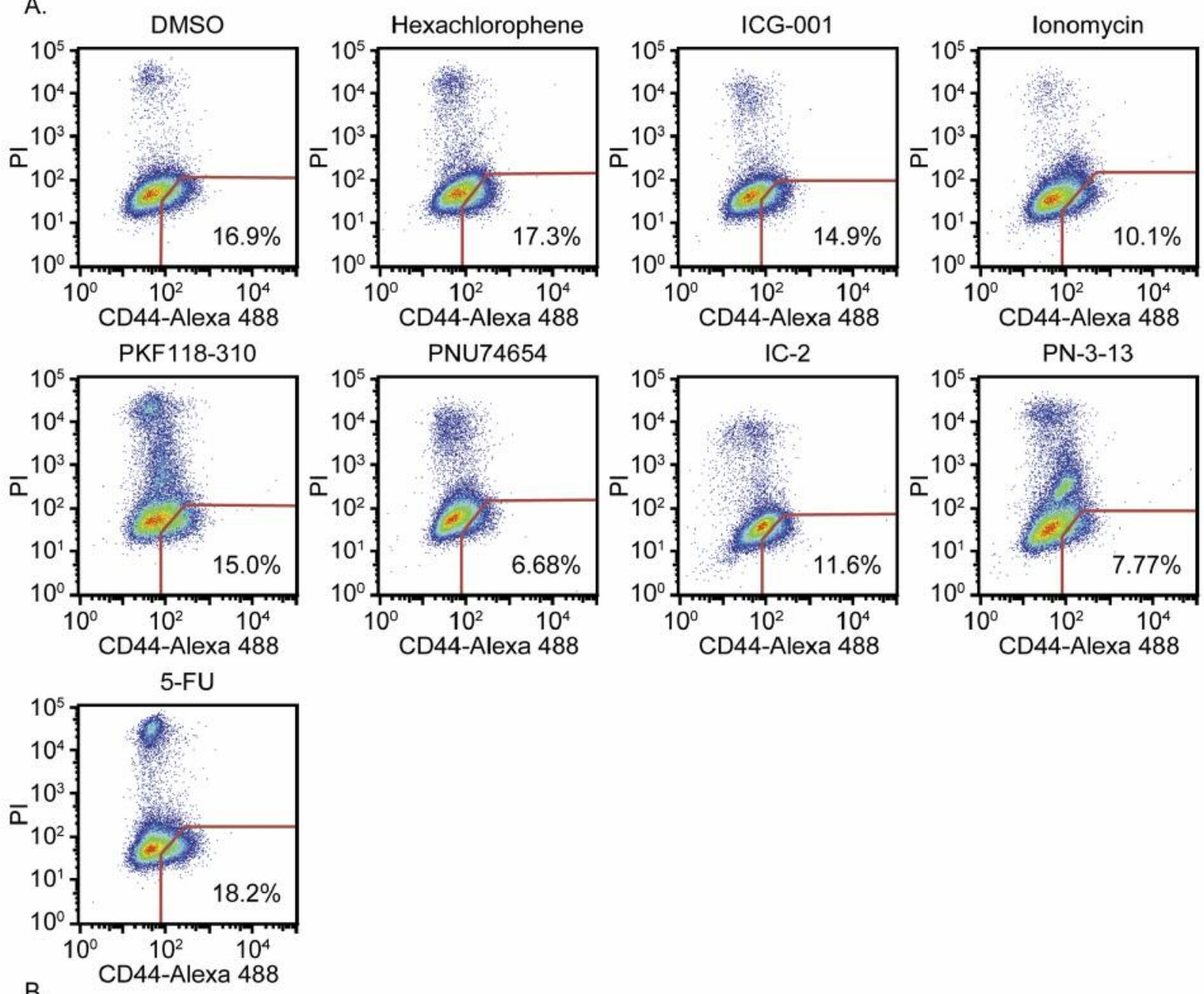

B

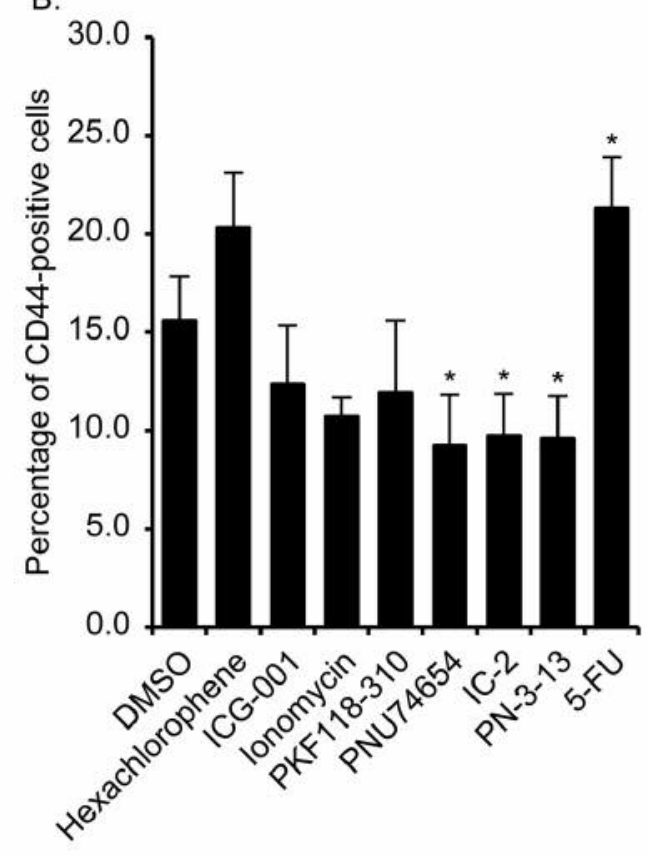

Figure 3. The effect of small-molecule compounds on CD44-positive $\mathrm{HuH7}$ cells. A: Representative flow cytometric analysis of CD44 expression in $\mathrm{HuH7}$ cells treated with small-molecule compounds. $\mathrm{HuH7}$ cells were treated with $1 \%$ dimethyl sulfoxide (DMSO), $15 \mu \mathrm{M}$ hexachlorophene, $15 \mu M$ ICG-001, $5 \mu$ M ionomycin, $5 \mu M$ PKF-118-310. $200 \mu M$ PNU74654, $50 \mu M$ IC-2, $10 \mu M$ PN-3-13, or $0.5 \mu M$ 5-fluorouracil (5-FU) for $48 \mathrm{~h}$ and stained with Alexa Fluor 488-labeled antibody to CD44 and propidium iodide (PI). The concentration of each small-molecule compound was that at which t-cell factor $4 / \beta$-catenin activity was suppressed to less than 50\% of the DMSO-treated control group. B: The fraction of CD44-positive HuH7 cells produced on treatment with the indicated compounds. Data are shown as the mean $\pm S D$ $(n=4)$. Statistical significance was determined by the Dunnett's test: significantly different from the control at $* p<0.05, * * p<0.01$. 
A.
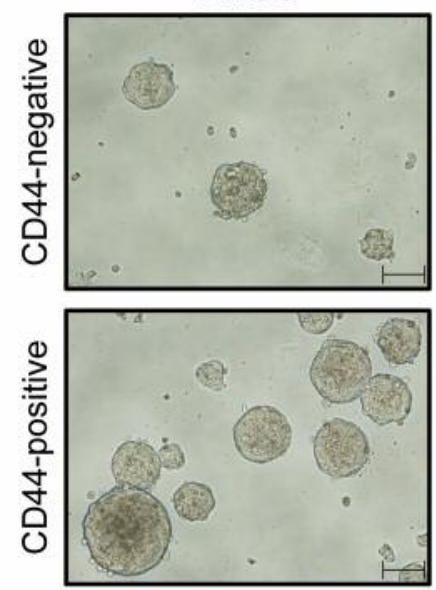

IC-2
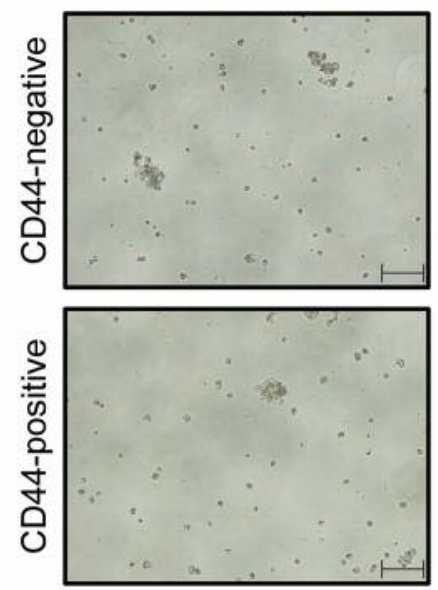

B.

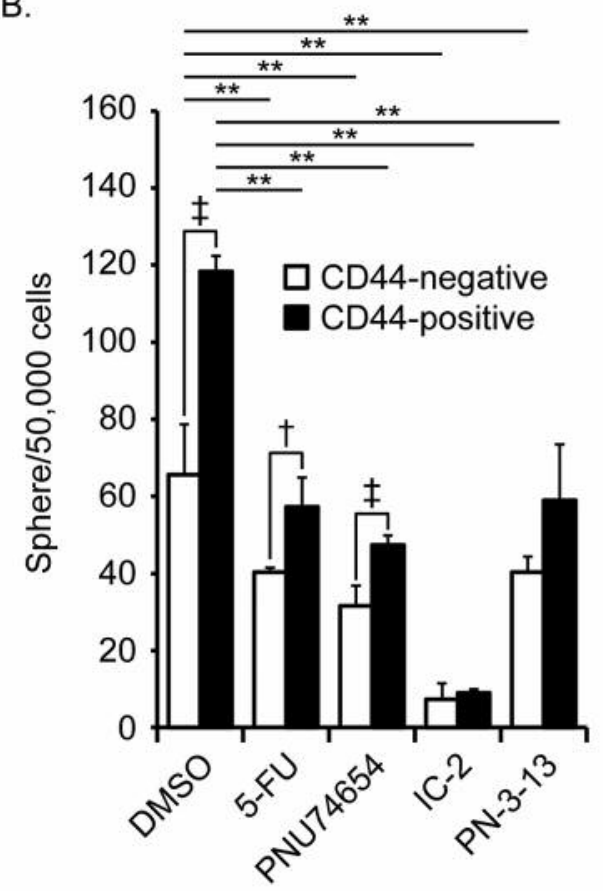

5-FU
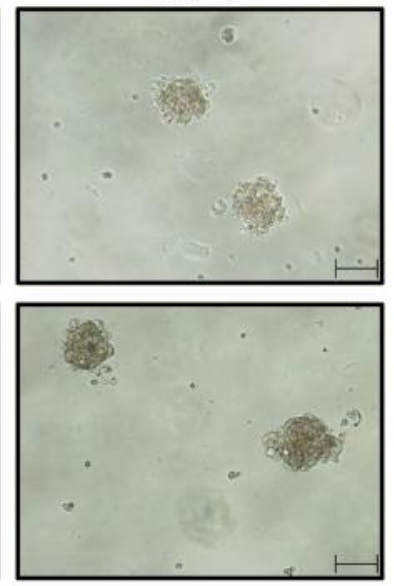

PN-3-13
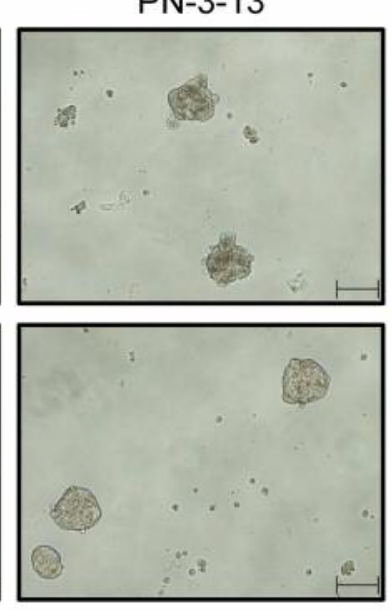

PNU74654
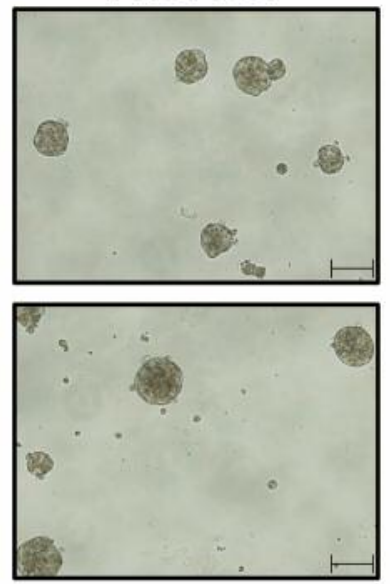

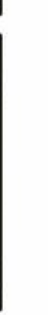



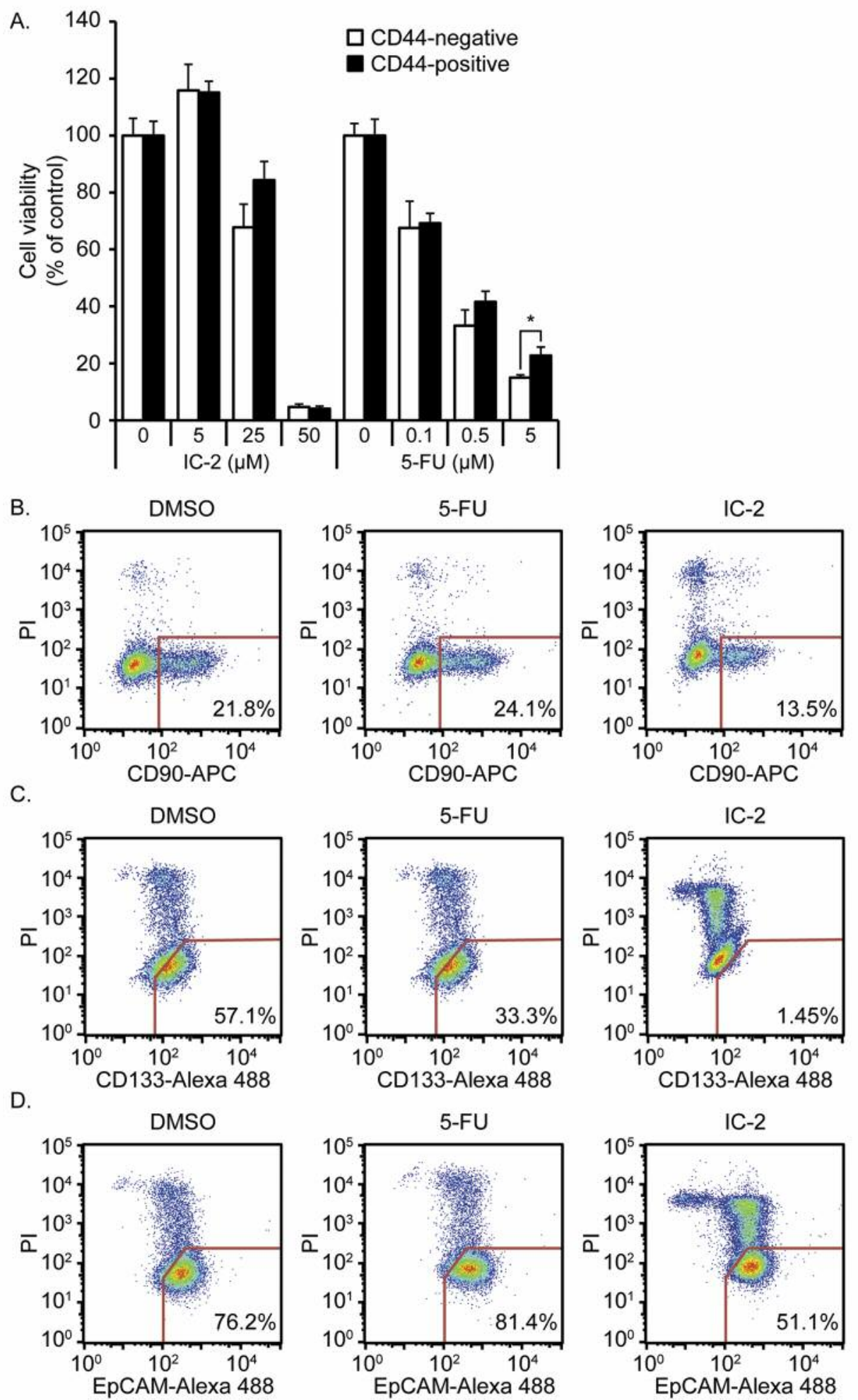

Figure 5. IC-2 significantly suppressed the cell viability of different CSCs. A: Viability of sorted CD44-positive and CD44-negative HuH7 cells treated with IC-2 or 5-fluorouracil (5-FU) for $96 \mathrm{~h}$. The value of cells treated with dimethyl sulfoxide (DMSO) was defined as 100\%. Data are shown as the mean $\pm S D(n=3)$. Flow cytometric analysis of HLF cells expressing CD90 (B), and of HepG2 cells expressing CD133 (C), or epithelial cell adhesion molecule (EpCAM) (D) after treatment with IC-2 or 5-FU. The percentage of positive cells are shown. Propidium Iodide (PI) was used to discriminate dead cells. Statistical significance was determined by the Student's t-test: significantly different at *p<0.05. 


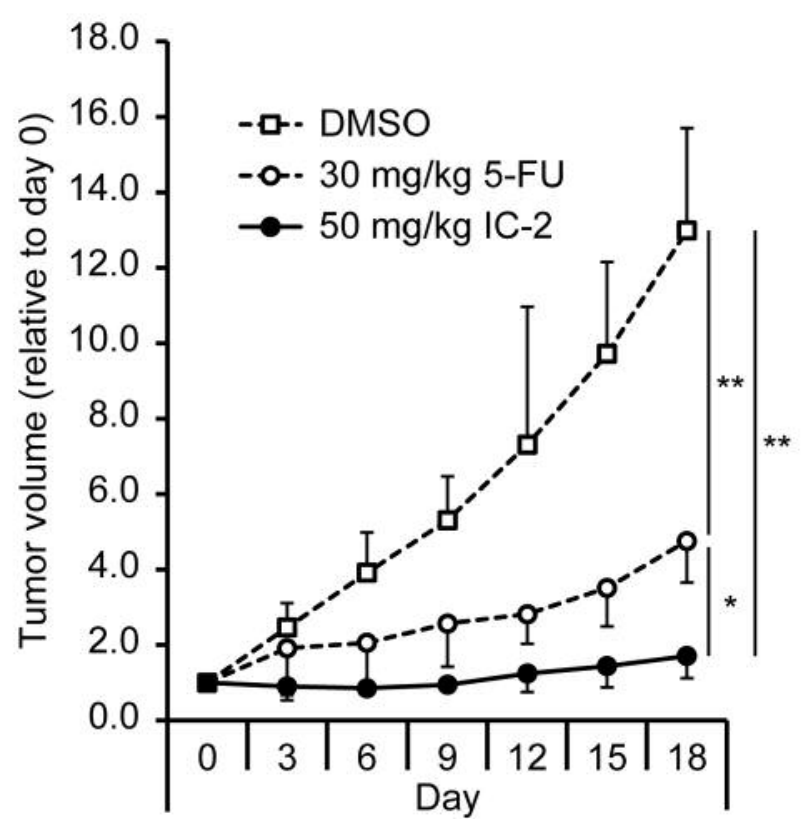

Figure 6. IC-2 suppressed tumor growth in a mouse xenograft model transplanted with CD44-positive HuH7 cells. The mice were treated with dimethyl sulfoxide (DMSO), $30 \mathrm{mg} / \mathrm{kg}$ 5-fluorouracil (5-FU), or $50 \mathrm{mg} / \mathrm{kg} I C-2$ for 18 days. The average tumor volumes are shown. Data are expressed as the mean $\pm S D(n=4-5)$. Statistical significance at 18 days was determined by the Dunnett T3 test: significantly different at $* p<0.05$ and $* * p<0.01$.

is reportedly regulated by the following two coactivators with different functions: $\mathrm{CBP}-\beta$-catenin complex mainly plays a role in the maintenance of stemness, pluripotency and tumorigenic phenotype, whereas p300- $\beta$-catenin complex is involved in the initiation of the differentiation program $(29,30)$. These reports and our findings suggest that suppression of $\mathrm{CBP} / \beta$-catenin-mediated transcriptional activity may be more critical for the elimination of liver CSCs, rather than simply disrupting the WNT signaling pathway. Indeed, IQ-1, which promotes compensatory interaction of CBP and $\beta$-catenin by inhibiting p300- $\beta$ catenin interaction, increased CSCs in breast and bladder carcinoma cell lines (31). Furthermore, CBP- $\beta$-catenin complex inhibition with ICG-001 reduced CSC properties, including drug resistance and sphere-forming ability, in nasopharyngeal carcinoma, ovarian cancer, and leukemia cells (32-34). Although the mechanism underlying inhibition of WNT signaling pathway and suppression of liver CSCs by IC-2 treatment has yet to be fully elucidated, it is reasonable to speculate that IC-2 suppresses liver CSC properties via inhibition of the CBP- $\beta$-catenin complex formation as ICG-001 does. Further examinations are required to elucidate the mechanisms of IC-2 action.
Among newly synthesized derivatives, although the antitumor effect of PN-3-13 was higher than IC-2 in two-dimensional (2D) monolayer culture, it was lower than IC-2 in three-dimensional (3D) culture. It has been reported that the sensitivity to antitumor drugs usually differs between $2 \mathrm{D}$ and $3 \mathrm{D}$ culture conditions, and the $3 \mathrm{D}$ culture system is superior for testing clinically active antitumor drugs $(35,36)$. Considering this aspect, IC-2 may have potential as a clinically active agent and serve as a promising therapeutic drug targeting liver CSCs. Note that in agreement with previous reports $(17,37)$, we observed that the clinically available drug, 5-FU, enhanced WNT-mediated transcriptional activity and relatively increased the population of CD44- or EpCAM-positive liver CSCs. Therefore, it needs to be taken into consideration that conventional chemotherapeutic agents may contribute to the acquisition of CSC-like properties and the basis for enrichment of CSCs.

In conclusion, we found that IC-2, a novel derivative of ICG-001, has a potent antitumor effect against HCC by suppressing liver CSC properties. Therefore, IC-2 may serve as a novel therapeutic agent for targeting liver CSCs in HCC.

\section{Financial Support}

This work was supported by Management Expenses Grants from Ministry of Education, Culture, Sports, Science and Technology in Japan.

\section{Acknowledgements}

The Authors are grateful to Dr. Keita Kanki (Okayama University of Science) for helpful comments and discussion and to Dr. Hiroyuki Tsuchiya (Tottori University) for his help in manuscript preparation.

\section{References}

1 Magee JA, Piskounova E and Morrison SJ: Cancer stem cells: impact, heterogeneity, and uncertainty. Cancer Cell 21: 283-296, 2012.

2 Reya T, Morrison SJ, Clarke MF and Weissman IL: Stem cells, cancer, and cancer stem cells. Nature 414: 105-111, 2001.

3 Visvader JE and Lindeman GJ: Cancer stem cells in solid tumours: accumulating evidence and unresolved questions. Nat Rev Cancer 8: 755-768, 2008.

4 Sakabe T, Azumi J, Umekita Y, Toriguchi K, Hatano E, Hirooka $\mathrm{Y}$ and Shiota G: Prognostic relevance of miR-137 in patients with hepatocellular carcinoma. Liver Int 37: 271-279, 2017.

5 Blanpain C: Tracing the cellular origin of cancer. Nat Cell Biol 15: 126-134, 2013.

6 Zhi XS, Xiong J, Zi XY and Hu YP: The potential role of liver stem cells in initiation of primary liver cancer. Hepatol Int 10 : 893-901, 2016.

7 Kreso A and Dick JE: Evolution of the cancer stem cell model. Cell Stem Cell 14: 275-291, 2014.

8 Ji J and Wang XW: Clinical implications of cancer stem cell biology in hepatocellular carcinoma. Semin Oncol 39: 461-472, 2012. 
9 Song W, Li H, Tao K, Li R, Song Z, Zhao Q, Zhang F and Dou K Expression and clinical significance of the stem cell marker CD133 in hepatocellular carcinoma. Int J Clin Pract 62: 1212-1218, 2008.

10 Yang ZF, Ho DW, Ng MN, Lau CK, Yu WC, Ngai P, Chu PW, Lam CT, Poon RT and Fan ST: Significance of CD90+ cancer stem cells in human liver cancer. Cancer Cell 13: 153-166, 2008.

11 Takebe N, Miele L, Harris PJ, Jeong W, Bando H, Kahn M, Yang SX and Ivy SP: Targeting Notch, Hedgehog, and WNT pathways in cancer stem cells: clinical update. Nat Rev Clin Oncol 12: 445-464, 2015.

12 Curtin JC and Lorenzi MV: Drug discovery approaches to target WNT signaling in cancer stem cells. Oncotarget 1: 552-566, 2010 .

13 Eaves CJ and Humphries RK: Acute myeloid leukemia and the WNT pathway. N Engl J Med 362: 2326-2327, 2010.

14 Reya $\mathrm{T}$ and Clevers H: WNT signalling in stem cells and cancer. Nature 434: 843-850, 2005.

15 Vermeulen L, De Sousa E Melo F, van der Heijden M, Cameron K, de Jong JH, Borovski T, Tuynman JB, Todaro M, Merz C, Rodermond H, Sprick MR, Kemper K, Richel DJ, Stassi G and Medema JP: WNT activity defines colon cancer stem cells and is regulated by the microenvironment. Nat Cell Biol 12: 468$476,2010$.

16 Vilchez V, Turcios L, Marti F and Gedaly R: Targeting WNT/beta-catenin pathway in hepatocellular carcinoma treatment. World J Gastroenterol 22: 823-832, 2016.

17 Yamashita T, Ji J, Budhu A, Forgues M, Yang W, Wang HY, Jia H, Ye Q, Qin LX, Wauthier E, Reid LM, Minato H, Honda M, Kaneko S, Tang ZY and Wang XW: EpCAM-positive hepatocellular carcinoma cells are tumor-initiating cells with stem/progenitor cell features. Gastroenterology 136: 1012-1024, 2009.

18 Lee SH1, Koo BS, Kim JM, Huang S, Rho YS, Bae WJ, Kang HJ, Kim YS, Moon JH and Lim YC: WNT/beta-catenin signalling maintains self-renewal and tumourigenicity of head and neck squamous cell carcinoma stem-like cells by activating Oct4. J Pathol 234: 99-107, 2014

19 Quan MF, Xiao LH, Liu ZH, Guo H, Ren KQ, Liu F, Cao JG and Deng XY: 8-Bromo-7-methoxychrysin inhibits properties of liver cancer stem cells via down-regulation of beta-catenin. World J Gastroenterol 19: 7680-7695, 2013.

20 Itaba N, Sakabe T, Kanki K, Azumi J, Shimizu H, Kono Y, Matsumi Y, Abe K, Tonoi T, Oka H, Sakurai T, Saimoto H, Morimoto M, Mabuchi Y, Matsuzaki Y and Shiota G: Identification of the small molecule compound which induces hepatic differentiation of human mesenchymal stem cells Regenerative Therapy 2: 32-41, 2015.

21 Itaba N, Matsumi Y, Okinaka K, Ashla AA, Kono Y, Osaki M, Morimoto M, Sugiyama N, Ohashi K, Okano T and Shiota G: Human mesenchymal stem cell-engineered hepatic cell sheets accelerate liver regeneration in mice. Sci Rep 5: 16169, 2015.

22 Lepourcelet M, Chen YN, France DS, Wang H, Crews P, Petersen F, Bruseo C, Wood AW and Shivdasani RA: Smallmolecule antagonists of the oncogenic Tcf/beta-catenin protein complex. Cancer Cell 5: 91-102, 2004.

23 Voronkov A and Krauss S: WNT/beta-catenin signaling and small molecule inhibitors. Curr Pharm Des 19: 634-664, 2013.

24 Park S, Gwak J, Cho M, Song T, Won J, Kim DE, Shin JG and Oh S: Hexachlorophene inhibits WNT/beta-catenin pathway by promoting Siah-mediated beta-catenin degradation. Mol Pharmacol 70: 960-966, 2006.
25 Park CH, Hahm ER, Lee JH, Jung KC, Rhee HS and Yang CH: Ionomycin down-regulates beta-catenin/TCF signaling in colon cancer cell line. Carcinogenesis 26: 1929-1933, 2005.

26 Wei W, Chua MS, Grepper S and So S: Small molecule antagonists of TCF4/beta-catenin complex inhibit the growth of HCC cells in vitro and in vivo. Int J Cancer 126: 2426-2436, 2010.

27 Gandhirajan RK, Staib PA, Minke K, Gehrke I, Plickert G, Schlösser A, Schmitt EK, Hallek M and Kreuzer KA: Small molecule inhibitors of WNT/beta-catenin/LEF-1 signaling induces apoptosis in chronic lymphocytic leukemia cells in vitro and in vivo. Neoplasia 12: 326-335, 2010.

28 Emami KH, Nguyen C, Ma H, Kim DH, Jeong KW, Eguchi M, Moon RT, Teo JL, Kim HY, Moon SH, Ha JR and Kahn M: A small molecule inhibitor of beta-catenin/CREB-binding protein transcription [corrected], Proc Natl Acad Sci USA 101: 1268212687, 2004.

29 Miyabayashi T, Teo JL, Yamamoto M, McMillan M, Nguyen C and Kahn M: WNT/beta-catenin/CBP signaling maintains longterm murine embryonic stem cell pluripotency. Proc Natl Acad Sci USA 104: 5668-5673, 2007.

30 Ma H, Nguyen C, Lee KS and Kahn M: Differential roles for the coactivators CBP and $\mathrm{p} 300$ on TCF/beta-catenin-mediated survivin gene expression. Oncogene 24: 3619-3631, 2005.

$31 \mathrm{He}$ K, Xu T, Xu Y, Ring A, Kahn M and Goldkorn A: Cancer cells acquire a drug resistant, highly tumorigenic, cancer stemlike phenotype through modulation of the PI3K/AKT/betacatenin/CBP pathway. Int J Cancer 134: 43-54, 2014.

32 Chan KC, Chan LS, Ip JC, Lo C, Yip TT, Ngan RK, Wong RN, Lo KW, Ng WT, Lee AW, Tsao GS, Kahn M, Lung ML and Mak NK: Therapeutic targeting of CBP/beta-catenin signaling reduces cancer stem-like population and synergistically suppresses growth of EBV-positive nasopharyngeal carcinoma cells with cisplatin. Sci Rep 5: 9979, 2015.

33 Nagaraj AB, Joseph P, Kovalenko O, Singh S, Armstrong A, Redline R, Resnick K, Zanotti K, Waggoner S and DiFeo A: Critical role of WNT/beta-catenin signaling in driving epithelial ovarian cancer platinum resistance. Oncotarget 6: 23720-23734, 2015.

34 Zhao Y, Masiello D, McMillian M, Nguyen C, Wu Y, Melendez E, Smbatyan G, Kida A, He Y, Teo JL and Kahn M: CBP/catenin antagonist safely eliminates drug-resistant leukemia-initiating cells. Oncogene 35: 3705-3717, 2016.

35 Imamura Y, Mukohara T, Shimono Y, Funakoshi Y, Chayahara N, Toyoda M, Kiyota N, Takao S, Kono S, Nakatsura T and Minami $\mathrm{H}$ : Comparison of 2D- and 3D-culture models as drug-testing platforms in breast cancer. Oncol Rep 33: 1837-1843, 2015.

36 Breslin S and O'Driscoll L: The relevance of using 3D cell cultures, in addition to 2D monolayer cultures, when evaluating breast cancer drug sensitivity and resistance. Oncotarget 7: 45745-45756, 2016.

37 Ma S, Lee TK, Zheng BJ, Chan KW and Guan XY: CD133+ HCC cancer stem cells confer chemoresistance by preferential expression of the AKT/PKB survival pathway. Oncogene 27: 1749-1758, 2008. 